\title{
Testing success factors for manufacturing BPR project phases
}

\author{
Tor Guimaraes • Ketan Paranjape
}

Received: 2 October 2012 / Accepted: 25 January 2013 / Published online: 8 February 2013

(C) The Author(s) 2013. This article is published with open access at Springerlink.com

\begin{abstract}
This study aims to identify prescriptions for success proposed in the literature and empirically test the relationships between proposed success factors and the extent to which each business process reengineering (BPR) project phase benefited from their presence. A usable sample of 212 top manufacturing managers (plant managers or above) shared their organizations' experience regarding their last BPR project implementation. The sample shows good representation based on company size (gross revenues industry subsectors), self-rated IT sophistication, top managers titles, and self-rated degree of knowledge about the specific BPR project implementation they have addressed. Results indicate that some success factors are more or less important to a particular project phase. Except for the insignificant relationship between project inception and process change/redesign phase, the relationships between the other phases are all significant and in some cases seem to represent a major determinant of success in the subsequent phase. The most important limitation is that new company processes will be developed in the future owing to changing regulations, improved services, new managerial policy, and/or new technologies. These processes may require different success factors; thus, researchers must continue their efforts to identify new success factors and empirically test their importance in practice. Managers can increase the chances for overall BPR project success and success in each phase by ensuring that the prescribed success factors are in place before they start or as they pursue the project. Several
\end{abstract}

\footnotetext{
T. Guimaraes $(\bowtie)$

Jesse E. Owen Chair of Excellence, Tennessee Tech University, Cookeville, TN 38505, USA

e-mail: tguimaraes@tntech.edu

K. Paranjape

Intel Corporation, 2111 N.E. 25th Avenue,

Hillsboro, OR 97124, USA

e-mail: Ketan.paranjape@intel.com
}

managerial insights and implications are discussed. BPR projects by their very nature are very expensive to prototype, forcing companies to follow a sequential methodology for changing and implementing new processes. This is the first study identifying and testing the success factors for each BPR project phase.

Keywords Business process reengineering - BPR project phases $\cdot$ Manufacturing $\cdot$ Success factors

\section{Introduction}

Business process reengineering (BPR) has been widely recognized as an important component of business innovation. Over the last decade, the definition for BPR and its success factors have been widely discussed. Traditionally, the definition for a BPR project calls for substantial changes to one or more business processes, in contrast with small incremental changes over time through smaller and many times more informal projects. BPR within the manufacturing sector has received considerable attention from researchers [12, $19,35,39,44-46]$ as to its benefits and success factors. BPR projects deal with "dramatic changes" to business processes, in contrast with a wide variety of methods which are mostly based on "continuous improvement." Some authors have also proposed BPR as an integral part of the product development process [13, 49]. While the promises from BPR project implementation among manufacturing companies have been impressive in many cases $[12,26,38,43,50$, $55]$, in practice the encountered failures and problems are also rather numerous $[33,34]$.

Historically, Cafasso [8] estimated that approximately one fourth of 300 reengineering projects in North America were not meeting their goals, and that for industry at large, the figure may be closer to $70 \%$. More specifically, many managers stated that the actual project benefits fell short of 
expectations along the dimensions of customer service, process timeliness, quality, cost reduction, competitiveness, improved technology, and revenues [25]. Despite the recognized importance of creating an environment in which reengineering will succeed [19,33-35], some companies in the past have had great difficulty successfully completing their BPR projects $[21,35]$. Succumbing to the pressure to produce quick results, many managers who implemented BPR have ignored the massive changes in organizational structure, misused and alienated subordinates, sold off solid businesses, neglected important research and development, and hindered the necessary modernization of their facilities $[11,32,35]$. With so many problems why are organizations still trying to implement BPR projects? Basically, they have no choice since the need for dramatic improvements to business processes are many times related to organization survival as well as prosperity $[12,13,26,38,46,49,51]$.

The more recent BPR implementations in the manufacturing area, in general, seem more successful than the reports from the last decade [19, 24, 52]. But risks and implementation problems still abound [9, 33-35, 48]. Specifically, some researchers have found that the required change process is far from easy and many projects have turned into learning experiences about how organizations should or should not manage major changes [28, 33, 48, 54]. A major question still remaining is whether or not the actions or factors proposed in the literature are necessary for success, if implemented will actually increase the chances for more successful company BPR projects in the future. Therefore, in this study, we identify the prescriptions for success proposed in the literature and empirically test the relationships between these proposed success factors and the expected benefits from each BPR project phase. In other words, the primary objective is to assess the extent to which the proposed success factors contributed to the success of each project phase. If this objective could be accomplished, BPR project managers could focus on ensuring that the proposed success factors are present before the next phase or the project is attempted. The next section defines each of the major constructs in this study: BPR project success factors and project phases. That is followed by sections on the methodology used, data analysis and results, and conclusions, implications and recommendations to managers and researchers.

\section{Literature review and theoretical framework}

\subsection{Major constructs}

Business process reengineering success factors are what managers should do to increase the likelihood that a BPR project will benefit their organization. The literature contains personal opinions and case studies prescribing one or more factors deemed important for BPR success. Most are common sense, such as driving BPR projects using customer demand, competitive pressures, and to improve financial performance $[18,19,35,41,46]$. Bringing in industry specialists, employee education, and reeducation are widely recognized. Employees must be taught the reengineering process, how it differs from existing work patterns, and what role they play [18]. Managers are also encouraged to reconsider reward mechanisms and to keep the reengineered organization moving forward, to instill the willingness to share information, and to use hands-on experience when redesigning processes [18, 54]. Farmer [17] proposes several important factors: (1) using project champions; (2) having an organized and well-disciplined attack plan; (3) employing a rigorous and detailed analytical process to develop a rough-cut design and identify major issues; (4) avoiding traditional thinkers as team members; (5) carefully setting up planning details for tooling, scheduling, maintenance, storage, etc., before implementation; (6) having a defined project structure [5]; (7) regularly scheduled meetings involving project manager with staff in all structural levels to focus attention; (8) using process mapping to distinguish productive activities from those that are non-value-added [14]; and (9) clearly defining and communicating the project's mission and vision. Bowns and McNulty [6], and Gulden and Reck [22] also list important factors: (1) reengineering results from large-scale changes to a business process, organizational structures, management systems and values, so executives must carefully target critical (though crossfunctional) business processes; (2) executives should correct organizational procedures focused on satisfying internal demands rather than the marketplace; and (3) focus on outcome rather than task. Other factors proposed are: (1) technology is viewed as an enabler, not a solution [27]; (2) let doers be the decision makers [23]; (3) use automation to reduce costs and response times [20]; (4) do not compromise quality improvements $[16,31]$; (5) project initiated and led by top managers accountable for the project's success $[6,29]$; (6) use surveys to find what's working; (7) be open about what you're doing, when, and why $[5,37,47]$; and (8) adopt an integrated planning approach [21, 54]. Success factors identified and collected from the literature are summarized in Table 1 which shows the arithmetic mean and standard deviation for each item based on the scale used. These figures indicate the general level of company implementation of each success factor and intercompany variance.

Many authors discuss BPR success factors without first explicitly defining BPR success, which we define as the extent to which, after being operational for at least 
Table 1 BPR success factors (extent to project showed these characteristics: $1=$ not at all, $2=$ minor extent, $3=$ moderate extent, $4=$ major extent, $5=$ great extent)

\begin{tabular}{|c|c|c|}
\hline & Mean & S.D. \\
\hline 1. Project leader has a politically powerful position in the organization hierarchy & 4.0 & 0.97 \\
\hline 2. Organization staff's commitment to continuous improvement & 2.8 & 1.22 \\
\hline 3. Process re-designers knew the processes from experience & 3.5 & 1.06 \\
\hline 4. Some process re-designers know the best way to perform the process & 3.0 & 1.28 \\
\hline 5. Competent IT people & 3.2 & 1.30 \\
\hline 6. Clear roles/tasks/expectations for project team members & 2.8 & 1.24 \\
\hline 7. BPR team focused on results not politics & 2.9 & 1.28 \\
\hline 8. IT personnel had a positive attitude & 3.1 & 1.21 \\
\hline 9. BPR project motivated by need for better performance and competitive pressures & 3.7 & 1.15 \\
\hline 10. BPR project team had representatives from all important departments & 3.4 & 1.23 \\
\hline 11. Target only a few critical (though cross-functional) business processes & 2.9 & 1.19 \\
\hline 12. View technology as an enabler, not a solution & 2.7 & 1.29 \\
\hline 13. IT support planning was highly integrated with reengineering process planning & 2.8 & 1.27 \\
\hline 14. Everybody was accountable for accomplishing their tasks and goals & 3.3 & 1.15 \\
\hline 15. There was good communication among BPR team members & 2.9 & 1.14 \\
\hline 16. There was a thorough process analysis to identify and eliminate non-value added activities & 2.6 & 1.22 \\
\hline 17. There was good feedback about what was working or not according to project plans & 3.2 & 1.16 \\
\hline 18. There were regularly scheduled meetings between project managers and staff at each level & 3.1 & 1.23 \\
\hline $\begin{array}{l}\text { 19. There was careful planning for project details such as tooling, scheduling, maintenance, system } \\
\text { user interfaces, quality, etc. before new process implementation }\end{array}$ & 2.6 & 1.21 \\
\hline
\end{tabular}

1 year, the project provided specific benefits to the whole organization. We studied the success factors' impact on BPR projects as they advanced through the major development/implementation process phases. Formally identifying project phases has been widely used for decades and BPR projects are no exception. Typically, the general phases include many possible task and subphases such as: feasibility assessment, project selection, project team formation, project planning, processes analysis and documentation, redesigning changes to existing processes and new processes, necessary resources acquisition and implementing planned changes, and adopting new processes and assessing results after a reasonable operational time. Different authors combine these BPR project lifecycle phases into fewer or more detailed frameworks depending on their objectives. The literature contains numerous references to project development and implementation methods thought to be useful for project success $[1,4,30,53]$. Proposed methods in some cases target specific tasks necessary to accomplish specific BPR project development/implementation phases $[3,15]$. In other cases, the proposed methods take a more holistic BPR development/implementation view $[2,4,36,40]$. For exploratory purposes, we chose a comprehensive but parsimonious BPR project development and implementation view, which encompasses five distinct general phases:
1. Project inception identifies and selects BPR projects whose importance is widely recognized by staff, projects where the managers involved all agree that it is likely to have widespread benefits, and/or projects considered winners among all investment alternatives.

2. Processes definition/analysis identifies and defines important processes involved and their relationships/linkages, ensuring that each process was well understood, how it was or has been performed and the project's added value to the organization.

3. Processes change/redesign ensures that proposed changes provide clear benefits from processes that are simplified and/or increased added value to the company by improving effectiveness and/or efficiency.

4. Changes implementation/adoption produces changed processes that are accepted by the affected employees and departments, and promotes good cooperation and support by all involved to ensure the new processes operate well.

5. Project benefits assessment when corporate managers and/or outsiders attempt to measure the results from the organization's BPR project investment after the changes have been operational for a reasonable time. This phase by far has been studied more widely and in greater depth. Many companies have derived significant benefits from their BPR experience. Researchers have 
Table 2 Extent to which this project phases show these characteristics/benefits $(1=$ not at all, $2=$ minor extent, $3=$ moderate extent, $4=$ major extent, $5=$ great extent)

\begin{tabular}{|c|c|c|}
\hline & Mean & S.D. \\
\hline 1. Project inception & 2.92 & 1.17 \\
\hline The need for the BPR project was well recognized in our company & 3.01 & 1.09 \\
\hline Managers agreed that the project would have widespread benefits for our company & 2.65 & 1.23 \\
\hline Project was the clear winner among all available investment alternatives & 3.09 & 1.22 \\
\hline 2. Processes definition/analysis & 3.14 & 1.05 \\
\hline The BPR team clearly identified the important processes and their relationships/linkages & 3.20 & 1.06 \\
\hline Each process was well understood and how it was performed & 3.28 & 1.03 \\
\hline The added value to the company from each process was well understood & 2.93 & 1.15 \\
\hline 3. Processes change/redesign & 3.10 & 1.11 \\
\hline Process changes clearly simplified and/or increased added value to the company & 3.17 & 1.09 \\
\hline Improved company effectiveness and/or efficiency was the main requirement behind process change & 3.02 & 1.19 \\
\hline 4. Changes implementation/adoption & 3.19 & 1.22 \\
\hline $\begin{array}{l}\text { The changed processes were readily accepted by } \\
\text { the affected employees and departments }\end{array}$ & 3.12 & 1.27 \\
\hline There was good cooperation and support by all involved to ensure the new processes operated smoothly & 3.26 & 1.21 \\
\hline 5. BPR project benefits & 3.08 & 1.29 \\
\hline Quality (improved products/services and related information) & 3.35 & 1.22 \\
\hline User/consumer satisfaction (i.e., quicker response to requests) & 3.14 & 1.30 \\
\hline Productivity (decreased cycle time, error rates, inventory, or cost) & 3.42 & 1.33 \\
\hline Profitability (increased assets, economic growth) & 2.33 & 1.42 \\
\hline Labor resources (improved employee morale, knowledge, and productivity) & 3.14 & 1.21 \\
\hline
\end{tabular}

reported major improvements in quality, customer satisfaction, productivity (reduced costs, time reductions, etc.), and profitability (return on assets, return on equity, etc.) at companies which completed reengineering projects $[5,6,12,18,29,41,43,55]$. The benefits vary dramatically from project to project and company to company, including: (1) reduced floor space and labor requirements, (2) material handling, (3) improved employee empowerment and morale, (4) improved communications between operational units, and (5) improved quality [17].

Based on the literature, desirable results expected from each phase and the organization benefits from BPR project operationalization are presented in Table 2 which shows the arithmetic mean and standard deviation for each item based on the scale used. The figures provide an indication of the general level of company success along each item and the intercompany variance.

\section{Study methodology}

\subsection{Questionnaire development}

As discussed earlier, the list of success factors and project phases with their respective tasks were assembled from the literature. For each item, a measuring scale was added for data collection. Some demographic items such as company size and IT sophistication were added to possibly detect response bias. Similarly, respondent demographics such as titles and knowledge about the BPR project were added to the questionnaire. Five practitioners with BPR experience and personally known to the researchers were asked to review and test the questionnaire. That is discussed further under Section 3.5.

\subsection{Sampling and data collection}

Researchers have found that managers who have a broad view of an organization are in the best position to address that organization's environment, available resources, workflow patterns, and values [7]. Therefore, for this study, top manufacturing managers are likely to be the most appropriate subjects regarding major changes to manufacturing processes. A national directory of manufacturing professionals was used to randomly select 1,500 top manufacturing managers. A usable sample of 212 top manufacturing managers (plant managers or above) shared their organizations' experience regarding their last BPR project implementation. The response rate of $14 \%(212 / 1,500)$ is normal for exploratory studies of this type. While these managers are based in the USA, many work for multinational companies with 
Table 3 Selected demographics

\begin{tabular}{lll}
\hline & Frequency & $\%$ \\
\hline Gross revenues (US dollars) & & \\
100 million (M) or below & 18 & 8 \\
101 to 500 M & 32 & 15 \\
501 to 999 M & 69 & 33 \\
1 to 5 billion (B) & 55 & 26 \\
5 B or above & 38 & 18 \\
Total & 212 & 100.00 \\
IT sophistication & & \\
Greatly below average & 5 & 2 \\
Below average & 31 & 15 \\
About average & 92 & 43 \\
Above average & 65 & 31 \\
Greatly above average & 19 & 9 \\
Total & 212 & 100.00 \\
Respondents title & & \\
Manufacturing VP or equivalent & 71 & 34 \\
Chief operating officer & 39 & 18 \\
Plant manager & 66 & 31 \\
Group of managers & 36 & 17 \\
Total & 212 & 100.00 \\
Respondents knowledge level about the specific BPR project & \\
Very high (directly involved with this BPR & 68 & 32 \\
$\quad$ implementation and results) & & \\
High (participated in several meetings about & 101 & 48 \\
Modis BPR implement and results) & & \\
$\quad$ implementation and results) & 43 \\
Low (just hearsay about this project) & 0 & 00.00 \\
None & 0 & \\
Total & 212 \\
\hline
\end{tabular}

manufacturing facilities in the USA. A questionnaire was sent directly to the top manufacturing manager with a cover letter explaining the purpose of the study, asking for participation, and offering to share the results. For this study, respondents were asked to address the questions regarding $\mathrm{BPR} /$ system implementation based on the most recent project (but fully operational for at least 1 year) of significance to their company, where at least "some of the processes involved were substantially redesigned."

\subsection{Sample description}

The sample demographics for the companies and the participants in this field test are presented in Table 3. The sample shows good representation based on company size (gross revenues), industry subsectors, and self-rated IT sophistication. Also, the sample shows good representation of top managers based on their titles and self-rated degree of knowledge about the specific BPR project implementation they have addressed.

\subsection{Construct measurement}

Respondents rated all items comprising the constructs below using the scales 1 (not at all), 2 (to a minor extent), 3 (to a moderate extent), 4 (to a large extent), and 5 (to a great extent). The average rating for the respective subitem represents the overall measure for each construct.

\subsubsection{Measuring success factors}

Table 1 factors, collected from the literature, were not automatically combined to represent a major success factor measure. Instead, as shown in Table 4, factor analysis, using Varimax rotation, produced five separate success factor subgroups. Therefore, subsequent analyses use these subgroups. Original success factor 19 loaded ambiguously into more than one factor so it was discarded.

\subsubsection{Measuring success in each project phase}

The BPR project development and implementation process encompassed the five general phases discussed earlier. Desirable results expected or benefits from each BPR development/implementation process phase, proposed in the literature, were provided for respondents to rate the extent to which each was true in relation to their particular BPR project. The average ratings and the standard deviation for each item are shown in Table 2. For each phase, factor analysis (not shown) produced a one-factor solution; thus, for each questionnaire, items were averaged to produce a measure for the specific phase results. These measures were used for further analysis.

Phase 1: Project inception - three items representing desirable results expected from this phase were presented to the respondents for rating: the need for the BPR project was well recognized in our company, managers agreed that the project had widespread benefits for our company, and among all investment alternatives, this project was the clear winner.

Phase 2: Processes definition/analysis - three items were presented to the respondents for rating: the BPR team clearly identified the important processes and their relationships/linkages, each process was well understood regarding how it was performed, and the added value to the company from each process was well understood.

Phase 3: Processes change/redesign - two items were presented to the respondents for rating: process changes clearly simplified and/or increased added value to the company, and improved 
Table 4 Factor analysis with Varimax rotation

Items

Factor Factor Factor Factor Factor

$\begin{array}{lllll}1 & 2 & 3 & 4 & 5\end{array}$

Factor 1: team cohesiveness

7. BPR team was focused on results not politics

10. BPR project team had representatives from all important departments

14. Everybody was accountable for accomplishing their tasks and goals

15. There was good communication among BPR team members

17. There was good feedback about what was working or not according to project plans

Factor 2: BPR process

6. Clear definition of roles/tasks/expectations for the project team members

12.View technology as an enabler, not as a solution

16. There was a thorough process analysis to identify and eliminate non-value-added activities

18.There were regularly scheduled meetings between project managers and each level of project structure

19. There was careful planning for project details such as tooling, scheduling, maintenance, system user interfaces, quality, etc. before new process implementation

Factor 3: process expertise

3. Process re-designers knew the processes from experience

4. Some process re-designers have best-in-kind process knowledge

11.Target only a few critical (though cross-functional) business processes

Factor 4: tech support

5. IT people were competent

8. IT personnel had a positive attitude

13. IT support planning for was highly integrated with reengineering process planning

Factor 5: leadership/motivation

1. Project leader has a politically powerful position in the organization hierarchy

2. Organization's commitment to continuous improvement

9. BPR project motivated by need for better performance and competitive pressures

Eigen values for each factor:

\begin{tabular}{lllll}
0.75 & 0.05 & 0.28 & 0.19 & 0.16 \\
0.76 & 0.13 & 0.22 & 0.25 & 0.17 \\
0.81 & 0.11 & 0.12 & 0.07 & 0.19 \\
0.77 & 0.17 & 0.05 & 0.19 & 0.25 \\
0.69 & 0.15 & 0.21 & 0.20 & 0.22 \\
& & & & \\
0.19 & 0.76 & 0.19 & 0.21 & 0.14 \\
0.26 & 0.71 & 0.13 & 0.30 & 0.15 \\
0.21 & 0.79 & 0.12 & 0.08 & 0.17 \\
0.32 & 0.67 & 0.28 & 0.19 & 0.13 \\
0.24 & 0.65 & 0.18 & 0.27 & 0.31 \\
& & & & \\
0.06 & 0.16 & 0.19 & 0.83 & 0.21 \\
0.23 & 0.24 & 0.28 & 0.73 & 0.34 \\
0.27 & 0.25 & 0.36 & 0.66 & 0.31 \\
& & & & \\
0.24 & 0.28 & 0.70 & 0.22 & 0.20 \\
0.34 & 0.29 & 0.63 & 0.30 & 0.22 \\
0.29 & 0.26 & 69 & 0.29 & 0.21 \\
& & & & \\
0.25 & 0.27 & 0.29 & 0.22 & 0.76 \\
0.28 & 0.23 & 0.29 & 0.26 & 0.72 \\
0.49 & 0.30 & 0.24 & 0.36 & 0.69 \\
& 4.23 & 3.58 & 3.41 & 3.33 \\
\hline
\end{tabular}

company effectiveness and/or efficiency was the main requirement behind any process change.

Phase 4: Changes implementation/adoption-two items were rated by the respondents: the changed processes were fully accepted by the affected employees and departments, and there was good cooperation and support to ensure the new processes operated smoothly.

Phase 5: Project benefits assessment-after completing the project and making the changes operational for at least 1 year, five major potential BPR benefits to the organization, as proposed in the literature, were provided. Respondents rated the extent to which each has been derived from the particular BPR project. content validity, the relevant literature was reviewed to understand each major construct's important aspects and components, and not to neglect any important dimension. To reduce nonrandom errors, the main threat to a construct's validity, practitioners with substantial experience managing major organization changes reviewed the questionnaire for validity (measuring the phenomena intended), completeness (including all relevant items), and readability (making it unlikely that subjects will misinterpret a particular question). A few questions were reworded to improve readability. As Table 5 indicates, the internal consistency reliability coefficients (Cronbach's alpha) for the study's scales are well above 0.5 deemed acceptable for exploratory studies [42].

\subsection{Measures validity and reliability}

Despite the study's exploratory nature, we took several precautions to ensure validity. Recommendations by Carmines and Zeller [10] were followed. To ensure

\section{Data analysis and results}

The statistical computations for this study are fairly simple and straight forward. Means and standard deviations (Tables 1, 2, and 5) were computed for the success factors and the BPR 
project phase's expected results/benefits. Since for each major variable we are using averages from several ordinal components, Pearson's correlation coefficients (Table 5) were computed to measure relationship strengths between each subgroup and the BPR expected results/benefits measures for each project phase. To eliminate multi colinearity among the success factors, Table 6 shows the results from the stepwise multivariate regression analysis. This table shows the variance (percentage) in the results/benefits measures for each phase which is explained by each success factor subgroup as it entered the regression equation. Significant total variance in the benefits measure was explained (percentages ranging from 43 to $65 \%$ ) by the success factor subgroups, providing strong support for the prescriptions on what needs to be done by managers to increase the likelihood that BPR projects will provide the expected results/benefits outlined in this study.

\section{Conclusions, implications, and recommendations}

The originality of this study comes from empirically testing the relationships between BPR success factors proposed in the literature and the actual benefits in practice. Currently, no other study examines BPR success factors at the project phase level, with the major implications for project management. While we originally expected that all the success factors proposed in the literature would be important to every BPR project phase, our results indicate that some success factors are more or less important to a particular project phase. Table 5 indicates that, except for the insignificant relationship between project inception and process change/redesign phase, the relationships between the other phases are all significant and in some cases seem to represent a major determinant of success in the subsequent phase. Table 5 also shows the most important factors necessary for success in a specific phase. Based on the specific order in which the independent variables entered the regression equation, Table 6 indicates the success factors that account for the largest percentage of the variance in the ratings for success in each phase. For example, leadership/motivation accounts for $27 \%$ of the variance in the ratings for project inception. Combined with team cohesiveness and process expertise available, these three variables explain $43 \%$ of the variance for the performance ratings in the project inception phase. Last, Table 7 summarizes and integrates the results presented in Tables 5 and 6 .

\subsection{Recommendations to practitioners}

Based on results shown in Table 7 , BPR project managers should increase the chances for success in each phase by ensuring that the corresponding success factors are in place. Some success factors' importance is pervasive to a greater or lesser extent to most project phases, i.e., available expertise about the processes being redesigned and having an 
Table 6 Multiple regression using stepwise method

\begin{tabular}{lll}
\hline & $\begin{array}{l}\text { Incremental R } \\
\text { squared }\end{array}$ & $\begin{array}{l}\text { Significance } \\
\text { level }\end{array}$ \\
\hline
\end{tabular}

Dependent variable: project inception

Independent variables ${ }^{\mathrm{a}}$ :

2. Team cohesiveness

0.27

0.00

3. Relevant process expertise

0.10

0.00

available

4. BPR process

0.06

0.02

5. Tech support

0.00

NS

Total variance explained

0.00

NS

Dependent variable: processes definition/analysis

Independent variables ${ }^{\mathrm{a}}$ :

$\begin{array}{llr}\text { 1. BPR process } & 0.20 & 0.00 \\ \begin{array}{l}\text { 2. Relevant process expertise } \\ \text { available }\end{array} & 0.15 & 0.00 \\ \text { 3. Team cohesiveness } & 0.09 & 0.00 \\ \text { 4. Tech support } & 0.03 & 0.05 \\ \text { 5. Leadership/motivation } & 0.00 & \mathrm{NS} \\ \text { Total variance explained } & 0.47 & \end{array}$

Dependent variable: processes change/redesign

Independent variables ${ }^{\mathrm{a}}$ :

1. Relevant process expertise available

0.30

0.00

2. BPR process

0.15

0.00

3. Tech support

0.04

0.02

4. Team cohesiveness

0.03

5. Leadership/motivation

0.00

0.04

NS

Total variance explained

0.52

Dep. variable: changes implementation/adoption

Independent variables ${ }^{\mathrm{a}}$ :

1. Team cohesiveness

0.32

0.00

2. Leadership/motivation

0.13

0.00

3. Tech support

0.08

0.00

4. BPR process

0.05

0.03

5. Relevant process expertise

0.02

NS available

Total variance explained

0.58

Dependent variable: BPR benefits

Independent variables ${ }^{\mathrm{a}}$ :

\begin{tabular}{lll} 
1. BPR process & 0.32 & 0.00 \\
2. Team cohesiveness & 0.14 & 0.00 \\
3. Tech support & 0.09 & 0.00 \\
4. Relevant process expertise & 0.06 & 0.02 \\
$\quad$ available & & \\
5. Leadership/motivation & 0.04 & 0.04 \\
Total variance explained & 0.65 & \\
\hline
\end{tabular}

NS not significant

${ }^{a}$ In the sequence which they entered the regression equation

effective BPR project management process. Also, results indicate that some success factors are primarily important to completing a particular project phase, e.g., strong project leadership and motivation success factor items are primarily important during the starting phase and the project's implementation phase when resources commitment and political issues may become more pronounced. Similarly, effective technical support becomes more pronounced during the two last project phases. Thus, it becomes an important objective for project managers to preemptively ensure that before the project starts, the required success factors will be in place as the project advances.

\subsection{A report card on overall benefits from company BPR} projects

Results indicate that many companies have derived many benefits from completing their BPR projects; however on average, company benefits have been rated only moderate. The extent to which companies are deriving specific benefits from their BPR projects can be seen in item 5 of Table 2 . The specific overall project benefits, which have been derived somewhere between a "moderate extent" and a "major extent," are represented by increases in productivity, improved service quality and personnel resources, and improved user/customer satisfaction from the reengineered processes. Unfortunately, increased company profitability has on average only been derived somewhere between "to a minor extent" and "a moderate extent."

Why is there so much difference in overall results from BPR projects among manufacturing companies, as indicated by the relatively large standard deviations? A strong clue is found in the wide diversity (also shown by relatively large standard deviations) in the extent to which individual companies are doing what has been recommended as important for successfully implementing BPR projects. The average and standard deviations for the items prescribed in the literature are shown in Table 1. On average, managers have "to a major extent" used BPR project leaders with politically powerful position in the organization hierarchy. The relatively small standard deviation around the average for this item shows that most companies are doing that. With a somewhat wider difference (larger standard deviation) in behavior, on average, companies have to a significant extent started their BPR projects motivated by competitive pressure and a need for better performance. On the other hand, BPR project managers ignore some prescriptions for increasing the likelihood of BPR success. While the variance from company to company is relatively wide, on average, they have only from a "minor extent" to a "moderate extent" followed some important prescriptions for success (i.e., commitment to continuous improvement, viewing technology as an enabler to implement business changes, performing a thorough process analysis to identify and eliminate process activities, which add no value to the ultimate target process beneficiaries, and carefully planning for project details before implementation). 
Table 7 Summary results for each phase

\begin{tabular}{|c|c|c|}
\hline Project phase & Desirable results (performance) measured by the extent of: & $\begin{array}{l}\text { Most important success } \\
\text { factors }\end{array}$ \\
\hline Inception & $\begin{array}{l}\text { - The need for the BPR project was well recognized by company staff } \\
\text { - The managers involved all agreed that the project has widespread benefits } \\
\text { for the company } \\
\text { - This project was the clear winner among all available investment alternatives }\end{array}$ & $\begin{array}{l}\text { - Strong leadership/motivation } \\
\text { - Team cohesiveness } \\
\text { - Relevant process expertise } \\
\text { available }\end{array}$ \\
\hline $\begin{array}{l}\text { Processes definition/ } \\
\text { analysis }\end{array}$ & $\begin{array}{l}\text { - BPR team clearly identified the important processes and their relationships/ } \\
\text { linkages } \\
\text { - Each process was well understood and how it was performed } \\
\text { - Added value to the company from each process was well understood }\end{array}$ & $\begin{array}{l}\text { - Effective BPR process } \\
\text { - Relevant process expertise available } \\
\text { - Team cohesiveness }\end{array}$ \\
\hline $\begin{array}{l}\text { Processes change/ } \\
\text { redesign }\end{array}$ & $\begin{array}{l}\text { - Process changes clearly simplified and/or increased added value to the } \\
\text { company } \\
\text { - Improved company effectiveness and/or efficiency was the main requirement } \\
\text { behind process change }\end{array}$ & $\begin{array}{l}\text { - Relevant process expertise } \\
\text { available } \\
\text { - Effective BPR process } \\
\text { - Effective technical support } \\
\text { - Team cohesiveness }\end{array}$ \\
\hline $\begin{array}{l}\text { Changes } \\
\text { implementation/ } \\
\text { adoption }\end{array}$ & $\begin{array}{l}\text { - Changed processes were readily accepted by the affected employees and } \\
\text { departments } \\
\text { - Good cooperation and support by all involved to ensure the new processes } \\
\text { operated smoothly }\end{array}$ & $\begin{array}{l}\text { - Team cohesiveness } \\
\text { - Strong leadership/ motivation } \\
\text { - Effective technical support } \\
\text { - Effective BPR process }\end{array}$ \\
\hline
\end{tabular}

Based on Table 4 results from factor analysis, the items prescribed in the literature as important for BPR success belong together as five separate groups addressing: (1) project team cohesiveness, (2) process used by the project team to implement the BPR project, (3) expertise available to the project team regarding the processes being redesigne$\mathrm{d} /$ reengineered, (4) IT support quality extended to the project, and (5) project leadership and motivation. At the bottom of Table 6, these five-factor groups explain $65 \%$ of the variance in the benefits derived from BPR projects. Thus, it behooves all managers in general, and BPR project leaders, to particularly focus attention on the items composing these groups, to ensure that before embarking on expensive BPR projects their organizations have these requirements for success in place.

Our study's results support the notion that ensuring project team cross-functionality is important. Fortunately, many companies have done that, but many did not and paid the price (lower benefits). It is important that the project team focuses on accomplishing BPR project results and not worry about politics within the BPR project team or within the particular department, which individual team members are representing. The team should have representatives from all departments related to the processes being redesigned and these representatives must be taught to communicate freely, receive/provide feedback on work progress and what is working according to the project plans. Despite creativity in process redesign, BPR team members must be taught that accountability for accomplishing their tasks and goals is an important ingredient for ultimate team success.
Another area deserving special attention from company managers is addressing what the BPR project team must do while performing their duties. Results indicate that, on average, team members are not doing as much as they probably should in this area. This is one area that may be viewed as bureaucratic, tedious work, requiring managerial discipline and some top-down cajoling. The prescribed factor groups are strongly correlated with the extent BPR benefits were derived, therefore the project team should: (1) clearly define roles, tasks, and expectations for individuals and the project team as a whole; (2) perform a thorough process analysis to identify and eliminate non-value-added activities as an integral process redesign effort; (3) have regularly scheduled meetings between project managers and team members, and for larger projects, meetings between managers and each organization level; (4) develop a detailed plan covering specific requirements such as personnel, tools, software, procedures, and maintenance before the project implementation phase starts; and (5) keep in mind that technology alone is never a solution but an enabler for the new/redesigned business processes.

Three factors (process expertise available, tech support effectiveness, and project leadership/motivation) are not as strongly correlated with the extent to which the organization derived BPR benefits. One might interpret that as if these factors are not as important as team crossfunctionality and how the BPR teams work. However, a more likely explanation may be that the relatively low standard deviations for these factors (indicating that most companies performed more evenly) provide lower 
discriminatory power thus lower correlations with the benefits from BPR projects. Nevertheless, it is important that company managers strive to: (1) improve their BPR team performance regarding process expertise, (2) not attempt to reengineer several processes all at once, (3) work closely with their IT department in general and particularly with BPR project IT requirement planners, (4) provide leadership and commitment for continuous improvement to the company's business processes, and (5) select BPR projects that have strategic importance.

\subsection{Study limitations and future research opportunities}

This study's two major objectives: (1) identifying prescriptions for manufacturing companies BPR project success proposed in the literature and (2) empirically testing the relationships between these success factors and the extent to which the BPR project benefits have been derived for each BPR project phase, were accomplished.

Nevertheless, our work has limitations that should be viewed as opportunities for future research such as understanding why/how individual success factors affect the success of different phases to varying degrees. The most important limitation is that, despite the extensive literature search and validation procedures, it is possible that other BPR success factors are neglected in the literature.

Quite likely, new company processes will be developed in the future owing to changing regulations, improved services, new managerial policy, and/or new technologies; these processes may require different success factors. Researchers must continue their efforts to identify new success factors and empirically test their importance in practice.

On the data analysis/research design side, a research opportunity stems from the need for longitudinal studies to more clearly establish cause and effect relationships between the main study variables. Multivariate statistical analysis should be conducted to identify variables that mediate or moderate the relationships between the BPR success determinants we studied and actual BPR benefits. Potentially important in this case is work exploring the importance of company size, industry sector as moderating variables. Other BPR success measures, which emphasize specific BPR project targets such as profitability, time to market, or customer satisfaction, may be more appropriate for measuring project success. Overall, despite these limitations, this study makes a significant contribution to improve the chances for manufacturing company BPR implementation success.

Acknowledgments The author is grateful to the board members of the National Association of Manufacturers who supported this study, to the many manufacturing managers who shared their knowledge and experience, and to Regina Gragg for her assistance with this project.
Open Access This article is distributed under the terms of the Creative Commons Attribution License which permits any use, distribution, and reproduction in any medium, provided the original author(s) and the source are credited.

\section{References}

1. Abdolvand N, Ferdowsi Z, Albadvi A (2007) Towards a unified perspective of business process reengineering methodologies. Int $\mathrm{J}$ Technology Transfer and Commercialisation 6(1):100-111

2. Adesola S, Bains T (2005) Developing and evaluating a methodology for business process improvement. Bus Process Manag J 11 (1):1463-7154

3. Aghdasi M, Albadvi A, Ostadi B (2010) Desired organisational capabilities (DOCs): mapping in BPR context. Int J Prod Res 48 (7):2029-2053

4. Bertoni M, Bordegoni M, Cugini U, Regazzoni D, Rizzi C (2009) PLM paradigm: how to lead BPR within the product development Field. Comput Ind 60(7):476-484

5. Blyth A (1998) A business process re-engineering success story. SIGGROUP Bulletin 19(1):21

6. Bowns IR and McNulty T (1999) Re-engineering Leicester Royal Infirmary. An independent evaluation of implementation and impact. School of Health and Related Research, University of Sheffield, Sheffield. ISBN 1900752115.

7. Buenger V, Daft RL, Conlon EJ, Austin J (1996) Competing values in organizations: contextual influences and structural consequences. Organ Sci 7(5):557-576

8. Cafasso R (1993) Rethinking reengineering. Computerworld 15:102-105

9. Cameron NS, Braiden PM (2004) Using business process reengineering for the development of production efficiency in companies making engineered to order products. Int J Prod Econ 89 (3):261-273

10. Carmines EG, Zeller RA (1979) Reliability and validity assessment. Sage, Thousand Oaks, p 63

11. Cascio WF (1993) Downsizing: what do we know? What have we learned. Acad Manag Exec 7(1):95-104

12. Chandna R, Ansari SR (2012) A literature review of business process reengineering of manufacturing systems. National Conference on Future Aspects of Artificial Intelligence in Industrial Automation, 2012, Proceedings published by International Journal of Computer Applications

13. Cooper R, Edgett S (2008) Maximizing productivity in product innovation. Res Tech Manag 51(2):47-58

14. Curtis B, Kellner MI and Over J (1992), Process modeling. Communications of the ACM, September, pp. 75-90

15. Doomun R, Jungum JV (2008) Business process modelling, simulation and reengineering: call centres. Bus Process Manag J 14 (6):838-848

16. Faier J, Shen D (1992) A telecom game plan for the 1990s. Telephony 19:31-37

17. Farmer JR (1993) Reengineering the factory. APICS, March, pp. $38-42$

18. Goll EO, Cordovano MF (1993) Construction time again. CIO $15: 32-36$

19. Gospodarevskaya E, Churilov L (2011) Process performance indicators in redesigning the patient care process. Bus Process Manag J 17(6):1012-1038

20. Green C (1992) Quality improvement—from dreams to reality. Canadian Business Review, Autumn, pp. 33-37

21. Grover V, Teng JTC, Fiedler KD (1993) Information technology enabled business process redesign: an integrated planning framework. Omega 21(4):433-447 
22. Gulden GK and Reck RH (1992) Combining quality and reengineering efforts for process excellence. Information Strategy: the Executive's Journal, Spring, pp. 10-16

23. Hammer M (1990) Reengineering work: don't automate, obliterate. Harvard Business Review, July-August, pp. 104-112

24. Hauser K, Paper D (2007) Simulation of business re-engineering processes: case study of a United States motor manufacturing company. Int J Manag 24(4):676-687

25. Hayley K, Plewa J, Watts M (1993) Reengineering tops CIO menu. Datamation 15:73-74

26. Hise P (2007) Feisty factories FSB: Fortune Small Business 17(5):22

27. Huff SL (1992) Reengineering the business. Business Quarterly, Winter, pp. 38-42

28. Jang K (2003) A model decomposition approach for a manufacturing enterprise in Business Process Reengineering. Int J Comput Integrated Manuf 16(3):210-218

29. Khandelwal VK, Lynch T (1999) Reengineering of the patient flow process at the Western Sydney Area Health Service. Proceedings of the 32nd Annual Hawaii International Conference on Systems Science 4:4017-4026

30. Klein M and Petti C (2006) A handbook-based methodology for redesigning business processes, Paper 221, <http://ebusiness.mit.edu $>$. Accessed 6 August 2011

31. Knorr RO (1991) Business process redesign: key to competitiveness. The Journal of Business Strategy, November/December, pp. 48-51

32. Koch C (2001) BPR and ERP: realizing a vision of process with IT. Bus Process Manag J 7(3):258-265

33. Kumar S, Harms R (2004) Improving business processes for increased operational efficiency: a case study. J Manuf Tech Manag 15(7):662-674

34. Lauonen M, Kess P (2002) Team roles in business process reengineering. Int J Prod Econ 77(3):205-218

35. Leu J, Huang Y (2011) An application of business process method to the clinical efficiency of hospital. Journal of Medical System 35 (3):409-421

36. Limam Mansar S, Reijers HA, Ounnar F (2008) Development of a decision-making strategy to improve the efficiency of BPR. Expert Syst Appl. doi:10.1016/j.eswa.2008.01.008

37. Margolis N (1992/1993) Voices of experience. Computer World, December 28th/January 4th, pp. 16-17

38. Martin K (2006) The trust factor. Ind Eng 38(3):30-15
39. Moore R (2007) Turn "little innovations" into big cost reductions. Plant Eng 61(2):25

40. Muthu, S., Whitman, L. and Cheraghi, S.H. (1999) Business process reengineering: a consolidated methodology. Proceedings of the 4th Annual International Conference on Industrial Engineering Theory, Applications and Practice, San Antonio, Texas

41. Nicholson J (1995) Patient focused care and its role in hospital process re-engineering. Int J Health Care Qual Assur 8(7):23-26

42. Nunally JC (1978) Psychometric theory, 2nd edn. McGraw-Hill, New York

43. Ozcelik Y (2010) Do business process reengineering projects payoff? Evidence from the United States. Int J Proj Manag 28 (1):7-13

44. Parker K (2007) Recognizing innovation in the global manufacturing enterprise. Manuf Bus Tech 25(10):18

45. Prajogo D, Laosirihongthong T, Sohal A, Boon-itt S (2007) Manufacturing strategies and innovation performance in newly industrialized countries. Ind Manag Data Syst 107(1):52

46. Ramanigopal CS, Palaniappan G, Hemalatha N, Murugan T (2011) Business process reengineering and its applications. Int J Manag Res Rev 1(5):275-288

47. Rasmus D (1992) Reengineering or evolution through violent overthrow. Manuf Syst 10(9):52-58

48. Rice MP, O’Connor GC, Pierantozzi R (2008) Implementing a learning plan to counter project uncertainty. MIT Sloan Management Review 49(2):54

49. Rowlands C (2006) The ideas factory. Works Manag 59(7):34-37

50. Teresko J (2004a) Lean, green and smart. Industry Week, May 5th, pp. $45-51$

51. Teresko J (2004) Manufacturing process optimization. Ind Week 253(12): 16

52. Teresko J (2008) Finding the next big thing. Ind Week 257(3):56

53. Thong JYL, Yap CS, Seah KL (2003) A consolidated methodology for business process reengineering. Int J Comput Appl Tech 17 (1): $1-15$

54. Walston SL, Burns LR, Kimberly JR (2000) Does reengineering really work? An examination of the context and outcomes of hospital reengineering initiatives. Health Serv Res 34(6):13631388

55. Yin G (2010) BPR application. Mod Appl Sci 4(4):96 